\title{
Clinicopathological study of neurological complications due to hypertensive disorders of pregnancy
}

\author{
AMANDA RICHARDS, DAVID GRAHAM*, ROSS BULLOCK \\ From the Departments of Obstetrics and Neurosurgery, University of Natal and Department of \\ Neuropathology, ${ }^{*}$ Institute of Neurological Science, Glasgow, Scotland, UK
}

SUMMARY Forty-three women with neurological complications secondary to eclampsia or severe pre-eclampsia were studied by CT scanning and in six intracranial pressure (ICP) monitoring was carried out. In seven women who died, neuropathological findings were correlated with clinical features. Cerebral oedema was present in 27 of the patients studied and the severity of oedema correlated to the duration of intermittent seizures. In five of the six women who had ICP measured, this was found to be transiently high. Intracranial haemorrhage was demonstrated in four of the $\mathbf{4 3}$ women, all of whom died. Hypoxic-ischaemic cerebral damage and fibrinoid necrosis were the most important neuropathological lesions identified. The management of neurological complications of eclampsia may be placed upon a more rational basis by an understanding of the mechanisms responsible for these lesions.

Neurological complications due to hypertensive disorders of pregnancy are the most common cause of maternal death from these disorders. ${ }^{1-3}$ However, the pathogenesis of these complications, namely eclamptic seizures, coma, visual disturbances and localising neurological defects, remains poorly understood. The purpose of this report is to document the neuropathological findings of seven women dying from eclampsia or severe pre-eclampsia. These changes are related to clinical and CT observations in a larger series of 43 women with pregnancy-induced hypertension (PIH) and one or more of the above mentioned neurological complications. The pathophysiological mechanisms which may have led to these lesions are reviewed.

\section{Patients and methods}

All patients in this series were treated at King Edward VIII Hospital, a referral centre for Black Africans in the Province of Natal. Due to inadequate antenatal care, eclampsia still occurs in approximately $1 \%$ of pregnant patients referred to this hospital. During a study period of 14 months, 192 eclamptic patients were treated in relation to approximately 19,000 deliveries.

Address for reprint requests: Mr M R R Bullock, Department of Neurosurgery, Institute of Neurological Sciences, Govan Road, Glasgow, Scotland, UK.

Received 14 July 1987 and in revised form 30 September 1987. Accepted 10 October 1987
Criteria for the diagnosis of eclampsia were as follows: (1) A diastolic blood pressure of $110 \mathrm{mmHg}$ or more, (2) $2+$ or more proteinuria on urinalysis (Albustix), (3) The occurrence of a seizure.

All patients were managed according to a standardised protocol, ${ }^{4}$ which included seizure and blood pressure control, intensive monitoring and cerebral CT when required. Termination of pregnancy was achieved by caesarean section or vaginal delivery as indicated. Where clinical status and CT findings suggested high intracranial pressure (ICP) monitoring ${ }^{5}$ was carried out in a neurosurgical intensive care unit with hyperventilation, mannitol, steroids and althesin infusion. Details of patient management are reported elsewhere. ${ }^{6}$ In those patients who died, and permission for necropsy was obtained, the brain or blocks of brain were retained for neuropathological evaluation after prolonged fixation in formol saline.

\section{Results}

Thirty-nine study patients underwent cerebral CT. In 27 evidence of brain oedema was present (table 1). Six of these patients underwent ICP monitoring, and in five, ICP was raised. Three patterns of cerebral oedema were demonstrated which, when correlated with duration of intermittent seizures experienced, patient recovery rate and measurement of ICP, tended to represent a spectrum of increasing severity (table 1).

Intracranial haemorrhage was identified on CT scan in four cases and in seven instances the cerebral CT scan was considered to be normal (table 1). 
Table 1 Clinical details and CT scan findings in 39 patients with neurological complication due to hypertensive disorders of pregnancy

\begin{tabular}{|c|c|c|c|c|c|}
\hline$C T$ finding & $\begin{array}{l}\text { Number of } \\
\text { patients }\end{array}$ & $\begin{array}{l}\text { Average } \\
\text { age (yr) }\end{array}$ & $\begin{array}{l}\text { Average } \\
\text { parity }\end{array}$ & $\begin{array}{l}\text { Mean duration } \\
\text { of seizures } \\
(h)\end{array}$ & $\begin{array}{l}\text { Number of } \\
\text { patients with } \\
\text { elevated ICP }\end{array}$ \\
\hline $\begin{array}{l}\text { Oedema } \\
\text { diffuse } \\
\text { watershed } \\
\text { occipital } \\
\text { Total }\end{array}$ & $\begin{array}{r}5 \\
9 \\
13 \\
27\end{array}$ & $\begin{array}{l}23 \\
18 \\
20 \\
20 \cdot 3\end{array}$ & $\begin{array}{l}1 \cdot 8 \\
0.4 \\
0.2 \\
0.8\end{array}$ & $\begin{array}{l}9.6( \pm 3.4) \\
5.8( \pm 1.0) \\
3.3( \pm 0.6) \\
6.4\end{array}$ & $\begin{array}{l}3 \\
2 \\
\overline{5}\end{array}$ \\
\hline Haematoma & 4 & 25 & $4 \cdot 6$ & $1.5( \pm 0.8)$ & - \\
\hline Diffuse hypoperfusion & 1 & 20 & 0.0 & 0.2 & - \\
\hline Normal & 7 & 26 & 1.4 & $1.0( \pm 0.5)$ & - \\
\hline
\end{tabular}

Neuropathological findings in seven patients (five eclamptic and two pre-eclamptic patients) have been correlated with clinical status and CT findings in table 2. Seven major neuropathological abnormalities were demonstrated:

(1) Vasculopathy (fig 1), acute vessel wall damage as evidenced by plasmatic vasculosis and fibrinoid necrosis was found in three of the seven patients. Changes were limited to the cortical regions in cases 1 and 4, whilst in case 2 only the brain stem was involved. Fibrin thrombi occluding abnormal vessels were only seen in case 1 .

(2) Perivascular microhaemorrhages were seen in three cases demonstrating vessel wall damage (fig 2). In case 4 there were multiple haemorrhages that ranged from 2 to $20 \mathrm{~mm}$ in size. This patient had a marked coagulopathy which appears to have exacerbated these haemorrhages.

(3) Perivascular micro-infarcts were identified only in case 1 . Lesions were limited to the cortex and were only seen in relation to damaged vessels.

(4) Oedema: pallor of staining and spongiosis were seen, not only in relation to micro-infarcts but also diffusely throughout the white matter of the posterior halves of the cerebral hemispheres. This feature was demonstrated in three cases and interpreted as oedema.

(5) Hypoxic ischaemic brain damage, as evidenced by the histological features of the ischaemic cell process, ${ }^{7}$ was present in five cases. In case 1 changes were limited to the cortex whereas in case 2 they were most marked within the arterial boundary zone between the distribution of the anterior and middle cerebral arteries. In contrast the damage was distributed diffusely in cases 3,6 and 7. In the latter two cases laminar necrosis, maximal in cortical layers 3,5 and 6 was a striking feature. This histological evidence of hypoxic damage ${ }^{7}$ is correlated with clinical episodes of hypotension and hypoxia in table 2 .

(6) Intracerebral haemorrhage. Subarachnoid and

Table 2 Clinical CT and neuropathological findings in 7 patients dying with hypertensive disorders of pregnancy

\begin{tabular}{|c|c|c|c|c|c|}
\hline Case & Age \& parity & $\begin{array}{l}\text { Duration of } \\
\text { seizures }(h)\end{array}$ & $C T$ findings & Significant clinical events & Neuropathological findings \\
\hline 1 & $20 / \mathrm{Pl}$ & 18 & $\begin{array}{l}\text { Diffuse oedema. } \\
\text { Basal cisterns } \\
\text { effaced }\end{array}$ & $\begin{array}{l}\text { ICP markedly elevated } \\
(80 \mathrm{mmHg})\end{array}$ & $\begin{array}{l}\text { Vasculopathy } \\
\text { Oedema } \\
\text { Hypoxic-ischaemic } \\
\text { damage cortex }\end{array}$ \\
\hline 2 & $18 / \mathrm{P} 1$ & 12 & Not done & $\begin{array}{l}\text { BP dropped to } 60 / 0 \\
\text { following post-caesarean } \\
\text { section sedation }\end{array}$ & $\begin{array}{l}\text { Vasculopathy } \\
\text { Oedema } \\
\text { Hypoxic-ischaemic damage } \\
\text { arterial boundary zone } \\
\text { Subarachnoid haemorrhage }\end{array}$ \\
\hline 3 & 23/P1 & Pre-eclamptic & $\begin{array}{l}\text { Normal brain ( } 4 \mathrm{~h} \\
\text { after cardiac arrest) }\end{array}$ & $\begin{array}{l}\text { Cardiac arrest following } \\
\text { administration of } \\
\text { Magnesium sulphate }\end{array}$ & $\begin{array}{l}\text { Diffuse hypoxic-ischaemic } \\
\text { damage }\end{array}$ \\
\hline 4 & 35/P6 & One fit & $\begin{array}{l}\text { Large intraventricular } \\
\text { bleed }\end{array}$ & $\begin{array}{l}\text { Caesarean section } \\
\text { revealed an abruptio } \\
\text { placenta of } 15 \mathrm{ml}\end{array}$ & $\begin{array}{l}\text { Vasculopathy } \\
\text { Subarachnoid and } \\
\text { intraventricular haemorrhage }\end{array}$ \\
\hline 5 & 18/P0 & Pre-eclamptic & Not done & $\begin{array}{l}\text { Dihydralazine infusion } \\
\text { resulted in profound } \\
\text { hypotension }\end{array}$ & No abnormality* \\
\hline 6 & 18/P0 & 4 & Occipital oedema & Cardiac arrest & $\begin{array}{l}\text { Diffuse hypoxic-ischaemic } \\
\text { damage }\end{array}$ \\
\hline 7 & 17/P0 & 6 & Not done & Cardiac arrest & Hypoxic-ischaemic damage \\
\hline
\end{tabular}

*Limited material available for examination. 


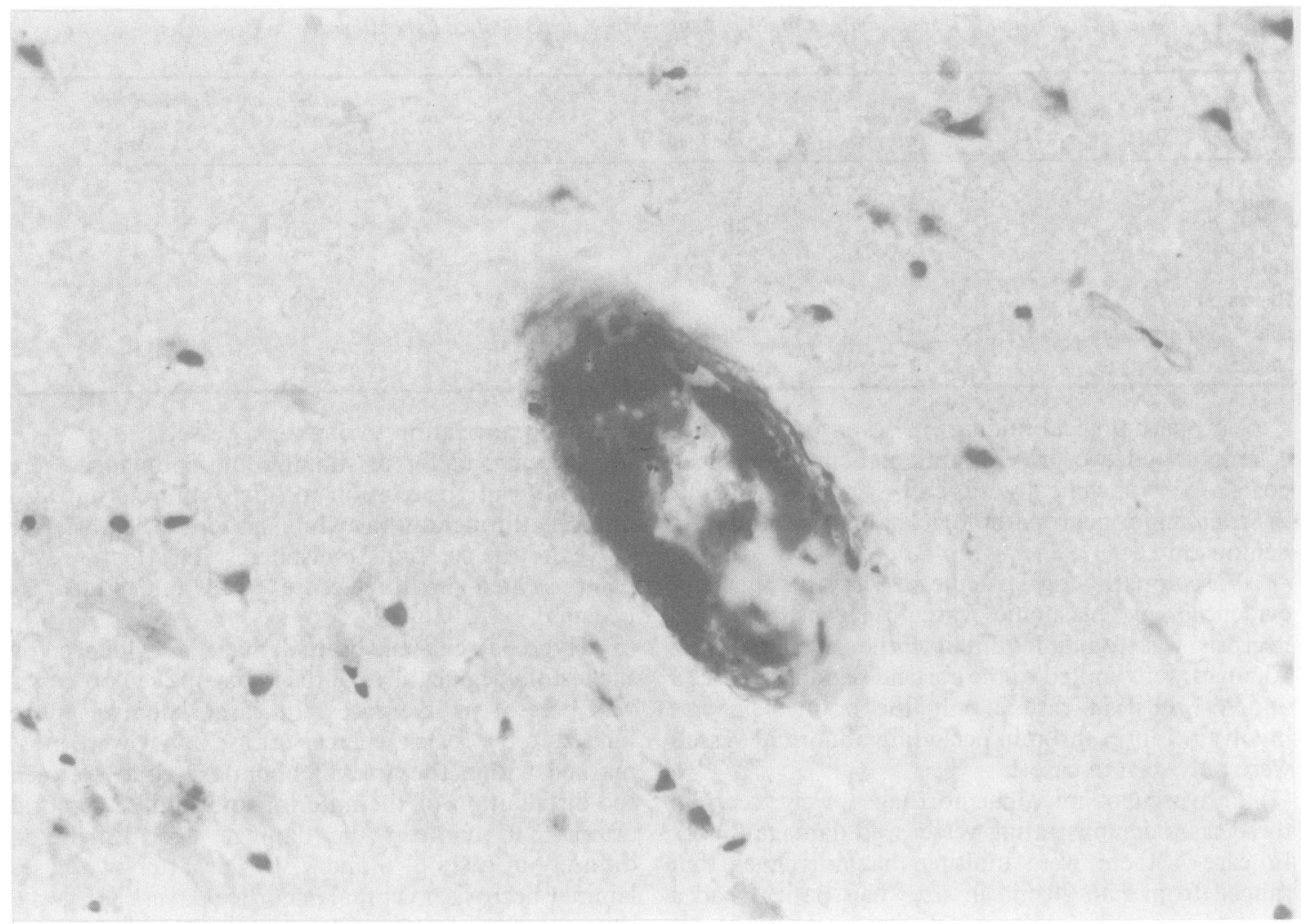

Fig 1 Vasculopathy, arteriolar lesion consisting of necrosis and thickening of the vessel wall demonstrated (Martuis scarlet blue stain $\times 285$ ).

intraventricular haemorrhage were identified in case 4 , both being extensions of multiple small intracerebral haemorrhages. A small amount of subarachnoid haemorrhage in the hypothalamic region was seen in case 2 .

(7) Evidence of transtentorial herniation due to raised ICP was identified in case 1 as bilateral wedges of necrosis in the medial parts of the temporal lobes. ${ }^{8}$

\section{Discussion}

Cerebral haemorrhage $^{910}$ and cerebral oedema ${ }^{61112}$ have been demonstrated on both CT scan and at necropsy in relation to eclamptic seizures. However, these neuropathological lesions have not hitherto been related to the clinical status of the patient and no pathological mechanisms have been postulated to inter-relate these lesions with our new finding of extensive hypoxic-ischaemic brain damage.

Vasculopathy Our findings suggest that the basic pathogenesis of CNS lesions in eclampsia is due to acute hypertensive vascular changes (fig 3). Vessel damage, or vasculopathy, demonstrated histologically in our patients was similar to those lesions found in hypertensive encephalopathy. ${ }^{13}$ Vasculopathy was not present in either of the two pre-eclamptic patients, but was found to be present in case 4 who had fitted only once (table 2). This suggests that vasculopathy develops either just prior to or with the onset of seizures. The extent of vessel damage, however, appeared to be proportional to the number of seizures experienced. Associated vascular thrombi were demonstrated only in case 1 who fitted intermittently for 18 hours.

Vessel wall damage occurring in acute hypertensive states is thought to be due to loss of autoregulatory capacity and "breakthrough" or over-stretching of vessel walls at mean arterial pressures (MAP) of over $140 \mathrm{mmHg} .{ }^{13-15}$ Worsening of vessel damage with recurrent seizures may therefore in part be explained by the fact that MAP rises considerably during each seizure. ${ }^{16}$ Animal studies have demonstrated blood brain barrier breakdown with extravasation of Evans Blue, a protein bound tracer, when "breakthrough" of MABP occurs. ${ }^{14}$ 


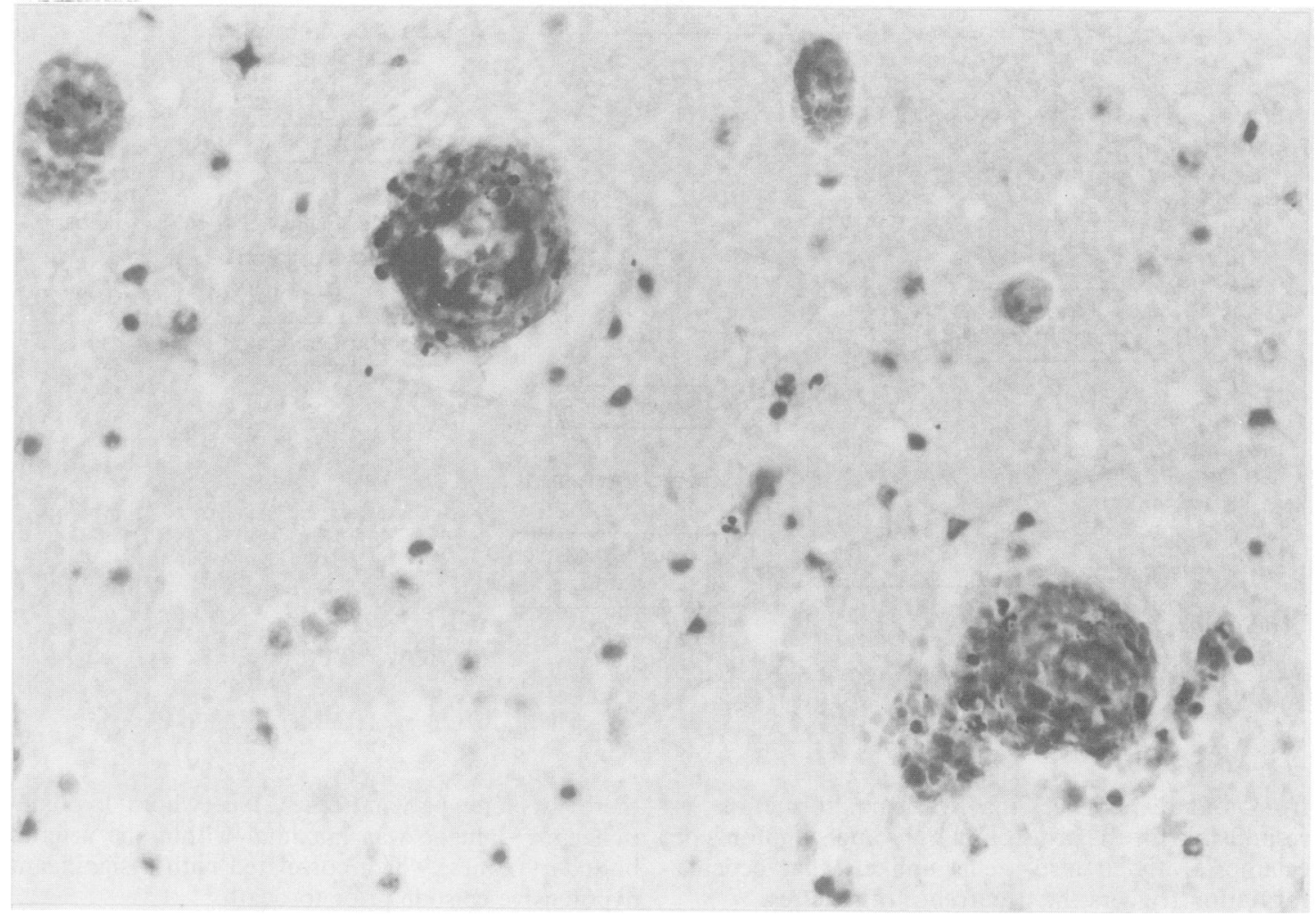

Fig 2 Perivascular microhaemorrhages (H\&E stain $\times 285)$.

The histological studies did not provide any evidence to suggest that vascular changes were localised to any specific regions of the brain. However, Govan $^{10}$ commented that petechial haemorrhages appeared predominantly in the occipital lobes in eclamptic patients. In addition, there is experimental evidence in animals that a tendency exists for hypertensive vascular changes to be most prominent in the arterial boundary zones of the cerebral hemispheres. ${ }^{141718}$ In an unpublished study of cerebral blood flow (CBF) in two eclamptics we have demonstrated increased CBF, most marked in the grey matter of the watershed or arterial boundary zone regions. We feel that this, plus the finding of cerebral oedema occurring predominantly in eclampsia in occipital and watershed areas supports the suggestion that cerebral vasculopathy develops in eclampsia as a result of hypertensive peaks and "breakthrough", which in turn results in dysfunction of the blood brain barrier and oedema formation (fig 3).

Intracerebral haemorrhages Large haemorrhages were not a common finding in our series of 43 patients (table 2). The pathogenesis of multiple small haemorrhages $(2-20 \mathrm{~mm})$ demonstrated within the cortical ribbon in case 4 remains uncertain; however, in some, but not all haematomas examined, there was either a centrally placed or closely associated vessel with evidence of vasculopathy. In addition, this patient had a severe coagulation disorder as shown by blood investigations and an abruptio placenta, the multiple haemorrhages may therefore have been exacerbated by thrombocytopenia as part of a disseminated intravascular coagulation syndrome. Coagulation disorders have frequently been demonstrated in eclampsia. ${ }^{19}$ Minimal reactive changes were demonstrated in association with haemorrhagic lesions, thus confirming their short duration.

Cerebral Oedema was suspected histologically by the pallor of staining and spongiosis of the neuropil. Cerebral oedema was previously thought to be the cause of clinical pre-eclamptic symptoms such as headache, nausea, vomiting and visual disturbances. However, we were not able to demonstrate oedema formation, either histologically or on CT scan in pre-eclampsia, or in eclampsia until a significant number of seizures had been experienced. Therefore, it seems unlikely 


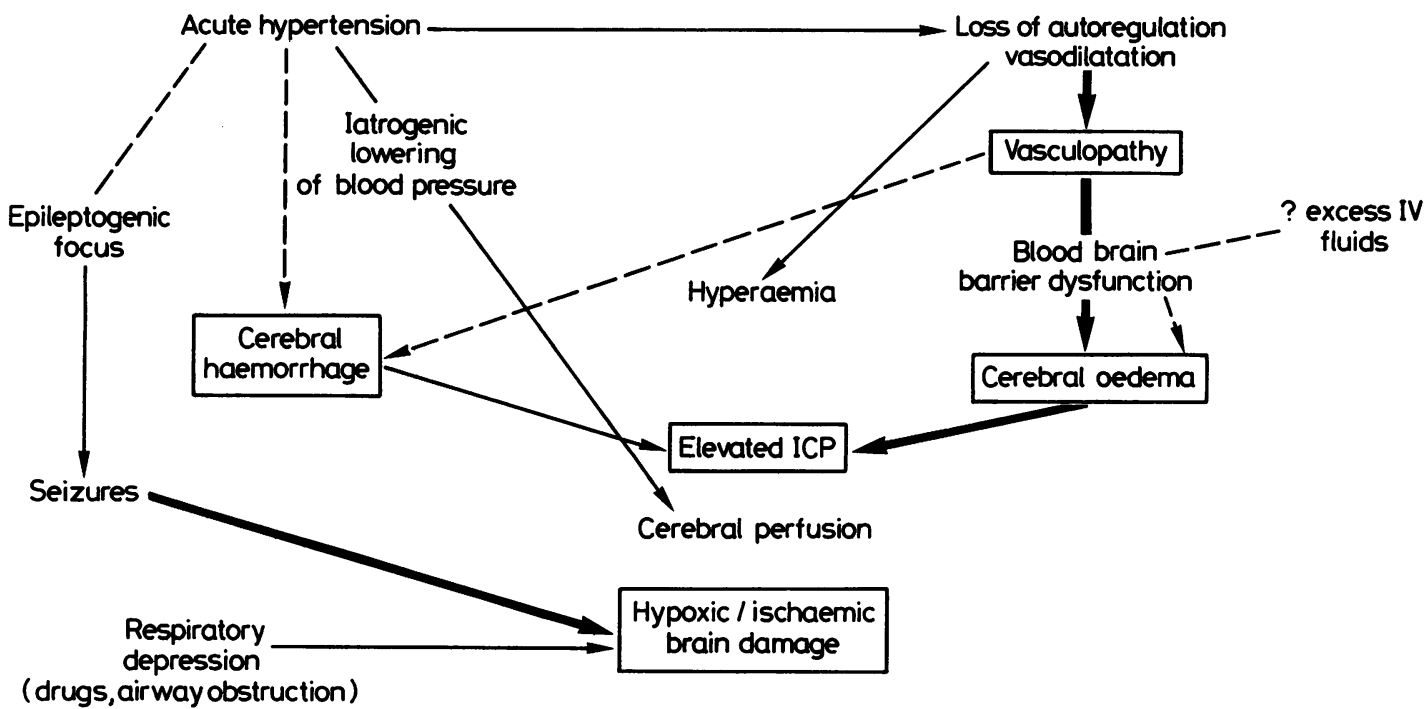

Fig 3 Proposed neurological pathophysiology of eclampsia.

from our experience that oedema formation is responsible for the prodromal signs and symptoms of eclampsia, and it also seems unlikely that oedema formation triggers the occurrence of seizures.

The aetiology of oedema formation in eclampsia remains unclear. However, our findings suggest that both vasculopathy and hypoxic-ischaemic damage are involved in the pathogenesis. With the loss of cerebral autoregulation and "breakthrough" cerebral vessel walls become permeated with plasma and undergo fibrinoid necrosis. Dysfunction of the blood brain barrier is thought to occur as a consequence of this damage. $^{2021}$ Dysfunction of the blood brain barrier would allow extravasation of plasma and plasma proteins into the brain substance with subsequent oedema formation (fig 3). ${ }^{22}$ In the most advanced cases of fibrinoid necrosis, frank diapedesis and perivascular haemorrhage may occur. ${ }^{1}$

Epilepsy is known to cause ischaemic brain damage which in turn is known to result in cytotoxic oedema formation ${ }^{23}$ and later as a result of hypoxic vessel damage, further vasogenic cerebral oedema may occur. 2021

Hypoxic-ischaemic damage Hypoxic-ischaemic brain damage was demonstrated in five of seven cases examined histologically (table 2). Two different distribution patterns were seen, each clearly reflecting clinical events. Firstly, widespread diffuse cortical damage was present in four cases which was attributed to poor cerebral perfusion in the face of extremely high ICP in case 1 and to cardiac arrest in cases 3,6 and 7. Second, there was one patient (case 2) in whom hypoxicischaemic damage was maximal within the arterial boundary zones, which correlated with a significant hypotensive episode prior to death. ${ }^{24}$

The pattern of widespread diffuse cortical ischaemia described in these five cases appeared to correlate with known episodes of cardiac arrest and high ICP. In two patients, this form of diffuse ischaemic damage was not present and neither of these had had extensive seizures. It is thus distinctly possible that prolonged seizures per se may have contributed to the diffuse laminar cortical ischaemia seen in cases $1,2,6$ and $7 .{ }^{7}$ The eclamptic vasculopathic process, with fibrinoid necrosis and peri-vascular haemorrhage appears to have produced the focal peri-vascular ischaemia (micro infarcts) seen in case 1 . This appears to be a distinct and separate form of focal ischaemic pathology upon which the more diffuse effects of seizure or hypotension-induced cortical ischaemia may be superimposed.

Pressure effects of elevated ICP were demonstrated in several cases on inspection of the brain at necropsy. this finding adds to both cerebral CT and ICP recording evidence that ICP may become elevated in eclampsia.

\section{Conclusion}

The management of the unconscious eclamptic patient may be placed on a more rational basis by an understanding of the pathophysiological mechanisms 
responsible for brain damage in this condition. There is evidence in favour of a form of hypertensive encephalopathy.

\section{References}

1 Donnelly JF, Lock FR, Winston-Salem NC. Causes of death in 533 fatal cases of toxemia of pregnancy. Am J Obstet Gynecol 1954;68:184-9.

2 Gibbs CE, Locke WE. Maternal deaths in Texas, 1968-1973. Am J Obstet Gynacol 1976;126:687-91.

3 Tomkinson J, Turnbull A, Robson G, et al. Report on confidential enquiries into maternal deaths in England and Wales, 1976-1978. London: Her Majesty's Stationery Office, 1978.

4 Moodley J, Norman RJ, Reddi K. Central venous concentrations of immunoreactive prostaglandins $\mathrm{E}, \mathrm{F}$ and 6-ketoprostaglandin $\mathrm{F}$ in eclampsia. $\mathrm{Br}$ Med $\mathrm{J}$ 1984;288:1487-9.

5 Teasdale E, Cardoso E, Galbraith S, Teasdale G. CT scan in severe diffuse head injury: Physiological and clinical correlations. J Neurol Neurosurg Psychiatry 1984;47:600-3.

6 Richards AM, Moodley J, Graham DI, Bullock MRR. Active management of the unconscious eclamptic patient. $\mathrm{Br} \mathrm{J}$ Obstet Gynecol 1986;93:554-62.

7 Brierley JB, Graham DI. Hypoxia and vascular disorders of the central nervous system. In: Adams JH, Corsellis JAN, Duchen LW, eds. Greenfield's Neuropathology. 4th ed. London: Arnold Press, 1984:125-207.

8 Adams JH, Graham DI. The relationship between ventricular fluid pressure and the neuropathology of raised intracranial pressure. Neuropathol Appl Neurobiol 1976;2:323-32.

9 Sheehan HL, Lynch JB. Pathology of Toxemia of Pregnancy. Baltimore: Williams \& Wilkins, 1973

10 Govan ADT. The pathogenesis of eclamptic lesions. J of Pathology and Microbiology 1961;24:561-75.

11 Benedetti GTJ, Quilligan EJ. Cerebral oedema in severe pregnancy induced hypertension. Am J Obstet Gynecol 1980; 137:860-2

12 Naheedy MH, Biller J, Schiffer M, et al. Toxemia of pregnancy. Cerebral CT findings. J Comput Assist Tomogr 1985;9: 497-501.

13 Chester EM, Agamanolis DP, Barker BQ, Vistor M. Hypertensive encephalopathy: a clinicopathologic study of 20 cases. Neurology 1979;28:928-39.

14 MacKenzie ET, Standgaard S, Graham DI, Jones JV, Harper M, Farrar J. The effects of acutely induced hypertension in cats on pial arteriolar caliber. Circulat Res 1976;39:33-41.

15 Skinhoj E, Strandgaard S. Pathogenesis of hypertensive encephalopathy. Lancet 1973;i:461-2.

16 Magnaes B, Nornes H. Circulatory and respiratory changes in spontaneous epileptic seizures in man. Eur Neurol 1974;12: $104-6$.

17 Dinsdale HB, Robertşon DM, Haas RA. Cerebral blood flow in acute hypertension. Xrch Neurol 1974;31:80-6.

18 Johansson B, Standgaard S, Jassen NA. On the pathogenesis of hypertensive encephalopathy. Circulat Res 1974;34:167-71.

19 Pritchard JA, Cunningham FG, Mason RA. Coagulation changes in eclampsia. Their frequency and pathogenesis. $\mathrm{Am} \mathrm{J}$ Obstet Gynecol 1976;124:855-63.

20 Brightman MW, Klatzo I, Olsson Y, Rees TS. The blood-brain barrier to proteins under normal and pathological conditions. J Neurol Sci 1970;10:215-39.

21 Klatzo I, Chui E, Fujiwara K. Aspects of the blood-brain-barrier in brain oedema. In: de Vlieger M, de Lange SA, Berks JWF, eds. Brain Oedema. New York: Wiley Medical Publication, 1981.

22 Brierley JB. Pathology of cerebral ischaemia. In: McDowell FH, Brennan RW, eds. General Vascular Diseases. New York: Grune \& Stratton, 1972:59-75.

23 Meldrum BS, Brierley JB. Circulatory factors and cerebral boundary zone lesions. In: Brierley JB, Meldrum BA, eds. Brain Hypoxia. London: William Heinemann Medical Books, 1971:20.

24 Lindheimer MD, Katz A. Hypertension in pregnancy. $N$ Eng $J$ Med 1985;313:675-9. 